\title{
Pais e Filhos em Psicoterapia: O Atendimento Clínico com uma Criança
}

Parents And Children In Psychotherapy: The Clinical Attendance To A Child

Padres E Hijos En Psicoterapia: La Atención Clínica Con Un Niño

Zuleica Pretto \&

Fabíola Langaro
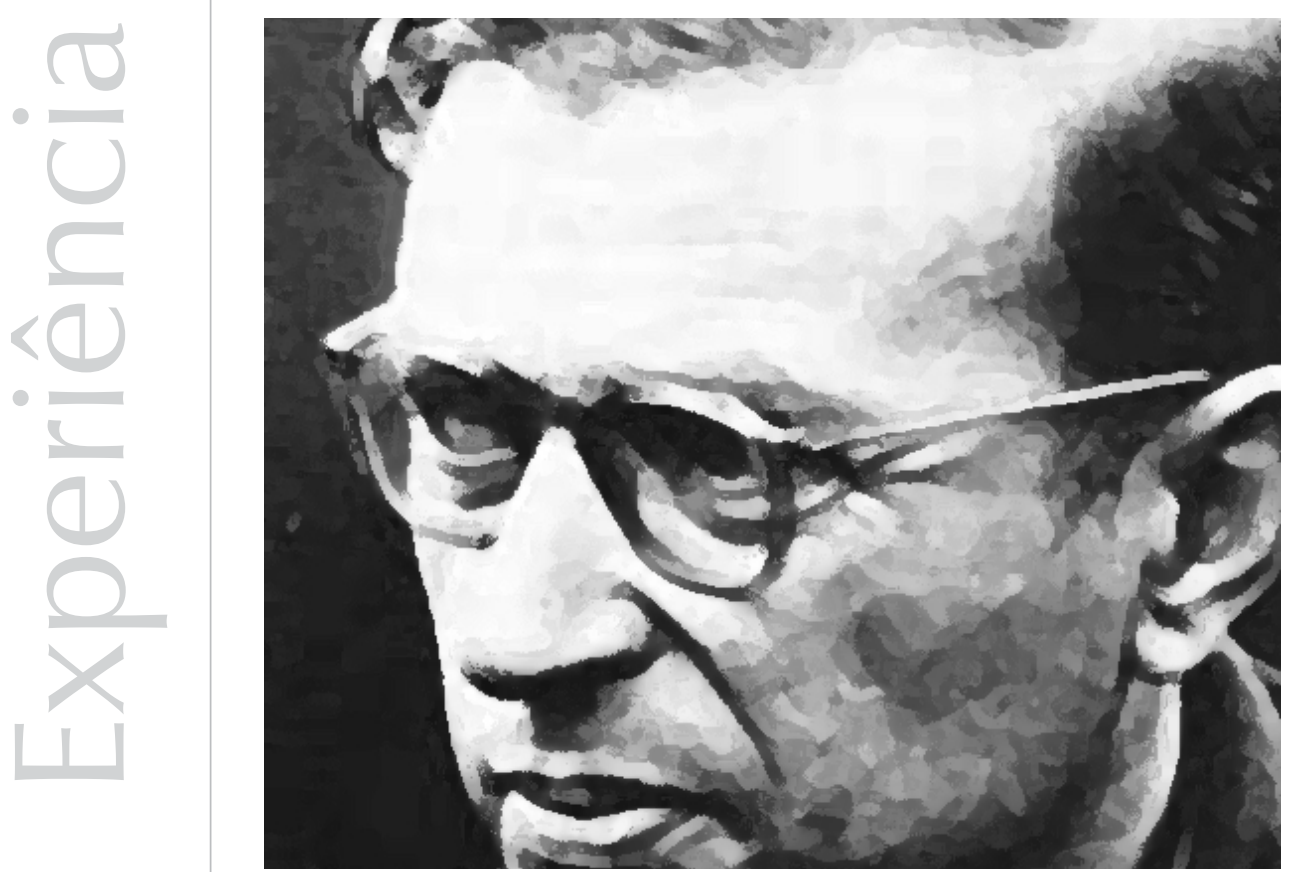
Resumo: Este artigo apresenta o relato de um processo psicoterápico realizado com uma criança com base na teoria existencialista de Jean-Paul Sartre. Nele são discutidas questões sobre a infância descritas pela teoria sartreana e por alguns autores existencialistas, bem como são desenvolvidas reflexões sobre esse período da vida e sobre seus desdobramentos para a constituição dos sujeitos. O processo psicoterápico aqui descrito envolveu a participação ativa da mãe da criança, e esse foi um fator considerado determinante para que mudanças na personalidade de ambos pudessem se efetivar. Além disso, a psicoterapia com base na teoria sartreana objetivou ser uma mediação capaz de auxiliar a criança a compreender a forma como estava sua personalidade se constituindo até então, promovendo mudanças em seu projeto-de-ser no intuito de que suas ações no mundo se tornassem, cada vez mais, condizentes com seu desejo. Destaca-se, assim, que ao final do processo, foi possível à criança, bem como à sua família, superar a situação de impasse e de sofrimento que os levaram a procurar o auxílio da Psicologia.

Palavras-chave: Criança. Psicologia clínica. Sarte, Jean-Paul, 1905-1980, Existencialismo.

Abstract: This article presents a description of a psychotherapeutic process carried out with a child based on the existentialist theory of Jean-Paul Sartre. In it, some issues of childhood described by Sartre's theory and some existentialist authors are discussed and some reflections about this period of life and its consequences for the constitution of personality are developed. The psychotherapeutic process described here involved the active participation of the child's mother and this was a factor considered crucial for the changes in the personality of the child in therapy. In addition, psychotherapy based on Sartre's theory aimed to help the child to understand how his personality was being constituted by then, making changes in his being project in order to achieve his desire. After all, it is considered that when the process was finished, it was possible for the child and his family to overcome the impasse and suffering that led them to seek the help of psychology. Keywords: Children. Clinical psychology. Sarte, Jean-Paul, 1905-1980. Existentialism.

Resumen: Este artículo presenta el relato de un proceso psicoterápico realizado con un niño con base en la teoría existencialista de Jean Paul Sartre. En este son discutidas cuestiones sobre la infancia descritas por la teoría sartreana y por algunos autores existencialistas, así como son desarrolladas reflexiones sobre ese período de la vida y sobre sus desdoblamientos para la constitución de los sujetos. El proceso psicoterápico aquí descrito involucró la participación activa de la madre del niño, y ése fue un factor considerado determinante para que cambios en la personalidad del sujeto en terapia pudiesen efectivarse. Además, la psicoterapia con base en la teoría sartreana demostró ser una mediación capaz de auxiliar al niño a comprender la forma como estaba constituyéndose su personalidad hasta entonces, promoviendo cambios en su proyecto de ser con la intención de que sus acciones en el mundo se volviesen, cada vez más, acordes con su deseo. Se destaca, así, que al final del proceso, le fue posible al niño, así como a su familia, superar la situación de impasse y de sufrimiento que les llevaron a buscar el auxilio de la Psicología.

Palabras clave: Niño. Psicología clínica. Sarte, Jean-Paul, 1905-1980. Existencialismo.

Em sua obra, embora Sartre não tenha dedicado parte especial de seu trabalho para discorrer diretamente sobre questões relacionadas à infância, há passagens em seus textos em que discute sobre as especificidades desse período e, de maneira mais marcada, sobre as relações de família. Através dessas passagens, é possível refletir sobre o campo das possibilidades delineadas pela condição de ser criança e que permeiam, então, a construção que o sujeito faz de si.

Partindo desse olhar, o objetivo deste artigo é, por um lado, retomar as questões sobre a infância propostas por Sartre e por alguns autores que se baseiam em suas obras e, por outro lado, apresentar o relato de um estudo de caso, fruto do processo psicoterápico de aproximadamente nove meses, realizado com uma criança de sete anos. Espera-se que essa produção possa oferecer bases iniciais para reflexões sobre esse período da vida e sobre seus desdobramentos para a constituição dos sujeitos, sob a perspectiva do existencialismo sartreano.

O primeiro ponto sobre a constituição do sujeito de que fala Sartre é que "a existência precede a essência". Isso significa "que o homem primeiramente existe, se descobre, surge no mundo, e que só depois se define. (...) O homem não é mais do que o que ele faz" (1978a, p.12). Assim, não há, para o existencialismo, natureza humana, visto que o homem não pode ser definido por qualquer conceito antes que seja concebido e que, por 
Para Sartre, "a verdade é que a subjetividade não é nem tudo, nem nada; ela apresenta um momento do processo objetivo (o da interiorização da exterioridade), e esse momento se elimina sem cessar, para sem cessar renascer novamente" (1978a, p. 125). isso, não se poderá achar em cada homem uma essência universal. O que existe é uma condição humana, que compreende "mais ou menos distintamente o conjunto de limites a priori que esboçam a sua situação fundamental no universo" (1978a, p.16).

Dessa forma, no momento em que a criança nasce, não há qualquer característica, traço ou condição biológica que, antes de sua inserção no mundo, seja capaz de determinar de que modo o sujeito irá se constituir. Apesar disso, ao nascer, a criança é lançada em um espaço social já permeado pelas relações - de expectativas, de sentimentos, de emoções - que as pessoas dela pertencentes já estabeleciam com ela antes mesmo de nascer. Assim, a maneira como sua mãe experiencia a gravidez e a forma como os sujeitos que participam direta ou indiretamente de sua gestação se relacionam com a criança delinearão as condições existenciais do início de seu processo de subjetivação/objetivação.

Nesse sentido, os horizontes iniciais para sua constituição estarão demarcados pela história e especificidade de sua família, como grupo constituído por sujeitos únicos, que se relacionam a partir de suas histórias e trajetórias particulares e também da história e da trajetória compartilhada por seus membros. É na complexidade desse espaço, então, que a criança irá encontrar mediações - condições materiais e históricas que compõem o conjunto de instrumentos de que dispõe para alterar sua condição - para iniciar seu processo de subjetivação (Sartre, 1978b).

Em um primeiro momento, a criança não se diferencia dos outros e das coisas e nem os diferencia entre si, sendo que as pessoas que a cercam, de certo modo, Ihe conferem uma identidade. Sua subjetividade, portanto, irá se constituir frente à situação em que é lançada, sentindo, pensando e fazendo algo com isso, apropriando-se do espaço social e psicológico que a cerca (Schneider, 2002). Para Sartre, "a verdade é que a subjetividade não é nem tudo, nem nada; ela apresenta um momento do processo objetivo (o da interiorização da exterioridade), e esse momento se elimina sem cessar, para sem cessar renascer novamente" (1978a, p. 125).

Essa apropriação, inicialmente, é efetivada de um modo alienado: a criança percebe e reflete espontaneamente sobre o mundo, encontrando-se tão absorvida no objeto que não há espaço para o seu eu (Schneider, 2002). Sendo assim, move-se em função de um ser futuro que tem que realizar, ou seja, de um projeto existencial que lhe é passado pelos outros. Esse futuro, então, acaba por definir suas escolhas cotidianas; assim, suas vivências, a identidade que the foi conferida e por ela apropriada, o que ela fez do que fizeram dela e de seu futuro, bem como seu desejo de ser, serão a base constitutiva de seu ser (Castro \& Schneider, 1998).

É possível, contudo, que, desde os seus primeiros anos de vida, a condição familiar da qual o sujeito participa se apresente permeada por contradições e impasses que inviabilizam a construção do projeto de ser da criança como ser único e responsável por suas escolhas. Ocorre que, muitas vezes, os sujeitos que constituem essa família estão impossibilitados de oferecer mediações que proporcionem a essa criança uma constituição como um ser capaz de enfrentar as adversidades do meio e de fazer escolhas reflexivas críticas diante de uma realidade que, impreterivelmente, the apresenta diferentes possibilidades, impondo a necessidade da escolha e, portanto, da ação.

Se isso ocorre, a criança poderá ser lançada em uma situação de insegurança ontológica, em que, frente às dificuldades enfrentadas em seu movimento no mundo, sentirá seu ser ameaçado (Laing, 1987). Diante, então, da falta de mediações para dar-lhe condições de superar essa situação de impasse, a criança poderá se complicar psicologicamente, ou seja, poderá, diante de acontecimentos concretos, experimentar "uma 'contradição de ser', em que a realidade the apresenta diferentes possibilidades, e, seja qual for o lado para o qual se dirigir, seu ser está comprometido" (Schneider, 2002, p. 291). 
Nessas circunstâncias, se há a busca pela psicoterapia, esse processo tem como função mediar o sujeito na construção de ferramentas que lhe possibilitem alterar uma situação de impasse. "Isso ocorre na medida em que o psicoterapeuta utiliza instrumentos e técnicas - como a descrição dos eventos ocorridos ao longo da história do sujeito e a reflexão sobre ela - para assessorar o indivíduo nas mudanças desejadas (Langaro, Santos, \& Pretto, 2009).

É um exemplo de como essa situação de impasse, que envolveu uma criança e sua família, e a sua superação ocorrida através de um processo psicoterápico, que será exposto no estudo de caso discutido a seguir. Vale destacar que o processo psicoterapêutico aconteceu em uma clínica Integrada de Atenção Básica à Saúde (CIABS), vinculada ao SUS e a uma universidade na região metropolitana de Florianópolis.

\section{Dados de identificação de Pedro ${ }^{1}$}

Pedro chegou à terapia com sete anos de idade. Morava com os pais, sendo o pai mestre de obras e a mãe, dona de casa. Tinha um irmão de 14 anos de idade. O pai, por não ter a possibilidade de se ausentar do trabalho no horário das sessões, não compareceu aos atendimentos.

\section{Problemática e compreensão do caso}

1 Este é um nome fictício. Ressalta-se que, na entrevista de triagem, os pacientes atendidos na Clínica de Atenção Básica à Saúde eram informados sobre as condições de trabalho, incluindo a possível utilização do material dos atendimentos para fins de pesquisa, quando então

assinavam um Termo de Consentimento Livre e Esclarecido para que o processo psicoterápico fosse iniciado.
Pedro foi levado à terapia pela mãe, aqui chamada de Maria, a partir de um encaminhamento realizado por um médico do Programa de Saúde da Família de um centro de saúde próximo à CIABS, por motivo de agressividade. Contudo, na primeira entrevista, em presença de Pedro, Maria fez queixas difusas, dizendo que o filho era uma criança "volúvel, de humor instável", verbalmente agressivo e não gostava de brincadeiras "tão normais", como de bola, mas de fazer trabalhos manuais e de escrever o tempo todo quando estava em casa.

Investigando-se a história de Pedro e de sua família, foi relatado que a gravidez de Pedro foi vivida pela mãe com muita dificuldade e necessidade de repouso. Ao nascer, mãe e filho tiveram incompatibilidade de sangue $A$ B O, o que causou icterícia no bebê. Pedro, segundo Maria, foi sempre muito frágil e precisou de cuidados que fizeram com que ela se dedicasse exclusivamente a ele; disse que o filho falava muito e exigia muito dela. Assim, a criança cresceu "grudada à mãe", gostando de brincar em casa, sendo muito criativo e ativo, "escrevendo" livros. Na escola, desde a primeira série, não queria mais escrever, relutando também para realizar os deveres de casa.

Com relação aos demais membros da família, a mãe relatou que o marido era pedreiro, e descreveu-o como "volúvel", afirmando que "é um bom pai, dá de tudo, mas muitas vezes sai de si e fala bobagem, depois se arrepende e pede desculpas. Mas a família dele é ignorante, o pai dele era alcoólatra, acho que vem de família ser nervoso, vem no sangue. Eu também sou nervosa, minhas unhas vivem um toco, sofro de depressão, meu humor é bipolar, e tem horas que eu não quero que as crianças falem comigo".

A partir das queixas de Maria, as sessões seguintes com Pedro foram dirigidas para descrever as situações em que ficava nervoso/ agressivo, a forma como se relacionava com as atividades da escola, com os familiares e com os amigos. Com isso, teve início o processo de investigação dos fenômenos e das variáveis que o compunham, conforme expõe Ribeiro (1992). Visava-se, assim, a compreender a problemática vivida por Pedro, a partir da queixa trazida, sendo elaborado um quadro objetivo de suas relações. Para saber o que precisaria ser modificado, tanto na materialidade como em sua compreensão reflexiva sobre suas relações .

Após os primeiros atendimentos, foi possível identificar que Pedro se sentia sozinho, não tinha muitos amigos, pois as brincadeiras das quais gostava - como fazer livros - eram brincadeiras solitárias, que seus colegas não gostavam de realizar e de compartilhar. Suas atitudes descritas como agressivas estavam 
relacionadas aos momentos em que insistia em praticar as atividades de que gostava e aos momentos em que se desentendia com seus colegas e com uma prima - sua vizinha -, que queriam geralmente realizar atividades das quais Pedro não gostava.

Com relação às dificuldades na escola, percebeu-se, ao longo das entrevistas com Maria, que esta não tinha "muita paciência" para ajudar Pedro nos deveres, e possuía uma atitude de cobrança com relação aos seus erros e ao "capricho", portanto, mais de exigência com relação ao filho que de compreensão e mediação. Maria, que não contava com a ajuda do pai para a divisão das responsabilidades da educação dos filhos, por estar cansada, muitas vezes exigia que o filho ficasse em silêncio, envolvido em uma única atividade e sem exigir sua atenção. Em outras situações, por desejar "fazer logo pra não se incomodar mais ainda", acabava fazendo "coisas por ele".

A história de necessidade de cuidado por questões de saúde da criança logo após seu nascimento - ocorrência de icterícia, de uma fratura na perna, de anemia e de adenóide - levou a mãe a centralizar as atenções e as preocupações nesse filho, o que fez que "se doasse muito, esquecendo até de si mesma". Essa situação representou o início de uma relação de dependência entre ambos que, naquele momento, gerava na mãe uma dificuldade de permitir ao filho a crescente conquista de independência.

Dessa forma, o cotidiano de Maria era preenchido por atividades basicamente relacionadas à maternidade, o que gerava a centralidade desse perfil em sua vida. Isso, por um lado, criava uma interdependência entre mãe e filho e, por outro, gerava também conflitos para a mãe em função de não haver espaço para a realização de outros perfis em sua vida (amoroso, profissional, amizade, etc.). Portanto, grande parte das queixas da mãe com relação a Pedro relacionava-se com o fato de seu olhar ser potencializado pela dinâmica de dependência que ela própria criava na relação com ele.
Assim, a partir das contradições de uma realidade que é sempre dialética, compreendeuse que Pedro, diante das exigências que a mãe Ihe fazia, de "saber fazer" tudo o que dele era esperado, bem como "de estar pronto" para não demandar dos pais a atenção requerida por qualquer criança que está em fase de desenvolvimento, estava gerando nele uma insegurança de ser, que promovia constantes momentos de solidão e o desmotivava a realizar as atividades que faziam parte de seu cotidiano, como a escola. Segundo Laing, uma pessoa segura "enfrentará todos os riscos da vida - sociais, éticos, espirituais e biológicos - com um firme senso da própria realidade e identidade, assim como a dos outros" (1987, p. 41). Por outro lado, uma pessoa insegura do ponto de vista ontológico, ou seja, do seu ser, possivelmente vivenciará circunstâncias comuns da vida como uma ameaça constante à sua existência.

As dificuldades de mediação dos pais, portanto, bem como a falta de tecimento entre os membros da família, não permitiam que Pedro compreendesse que suas amizades dependiam de seu investimento, como a participação em brincadeiras coletivas, por exemplo. Ainda, a falta de instrução para a realização das tarefas da escola e a desvalorização das atividades intelectuais que gostava de realizar o impediam de compreender a importância de seu envolvimento com os estudos formais, fazendo que ele se afastasse cada vez mais de suas atribuições. Esse posicionamento, por sua vez, aumentava as exigências da mãe, sendo criada uma dinâmica geradora de conflitos entre os dois.

A partir da compreensão possibilitada pelas entrevistas iniciais, foi possível estabelecer o plano de intervenção que orientou o trabalho realizado em psicoterapia, bem como a construção dos objetivos para cada sessão realizada. Ressalta-se, ainda, que tais planejamentos também ocorreram em um processo dialético, tendo sofrido alterações conforme novas informações foram surgindo. A seguir, está explicitado o planejamento do processo, com a descrição dos objetivos da terapia. 


\section{Plano de intervenção}

O plano de intervenção constou fundamentalmente de dois aspectos: 1) a demarcação das relações de Pedro com a família, os amigos e a escola, ao mesmo tempo em que foi estabelecida mediação para que as mudanças desejadas por ele pudessem ocorrer em seus perfis de filho/amigo/estudante, 2) processo de esclarecimento com a mãe de Pedro sobre a forma como ela estava vivenciando as dificuldades e o período da infância do filho, para que pudesse compreender que precisaria mediá-lo em suas dificuldades, já que o desenvolvimento da criança precisa ser assistido e que a forma como ela o estava fazendo - que gerava nele os comportamentos indesejáveis por ela - estava impregnada de suas próprias dificuldades como mãe.

Para as mudanças desejadas no primeiro aspecto, foram sendo demarcadas - por meio da descrição dos eventos, da reflexão e com o auxílio de desenhos e figuras - as relações de Pedro com a escola, com os estudos e com as atividades intelectuais, as relações de amizade, com a compreensão das brincadeiras realizadas por ele, a forma de estar com seus colegas e amigos e suas relações com a mãe, o irmão e com o pai, visando a demarcar o que poderia ser modificado para que a relação de dependência que estava sendo criada com a mãe fosse superada, com vistas ao desenvolvimento de sua autonomia.

2 Nota-se, aqui, que a palavra alteridade, em Sartre, é utilizada com sentido diferente daquele do senso comum. O contrário da experiência da alteridade é a reciprocidade, em que há o

"reconhecimento do outro enquanto liberdade, que viabiliza, portanto, a troca com o outro, onde um pode ser mediação para o outro" (Şchneider,

2002, p. 219). gerava a sobrecarga de fazer escolhas e de tomar atitudes sozinha que, ao mesmo tempo em que a angustiavam, potencializavam sua dinâmica de ocupar-se fundamentalmente de atividades que reforçavam a centralidade do perfil de mãe, a dificuldade de entender que o outro pode ser diferente do que ela era ou do que ela esperava que ele fosse e de que isso não impediria de esse outro realizar seus desejos e projetos e de se tornar um ser humano realizado, ou seja, foram trabalhadas as situações de alteridade, em que "o outro é sempre considerado outro, não há tecimento, não há flexibilidade, não há dialética" (Schneider, 2002, p. 219)².

São apresentadas, a seguir, as descrições relativas à evolução clínica de Pedro, desde o momento em que chegou à terapia até a sua alta.

\section{Evolução clínica}

Para a descrição dos fenômenos, foi utilizada com Pedro a elaboração de desenhos, tais como o tema livre da sua família, as coisas das quais gostava, a escola e as profissões que conhecia. Em todos os desenhos e colagens, mostrou-se bastante interessado nas atividades propostas, sendo capaz de manter-se concentrado nas tarefas durante todo o tempo das entrevistas. Suas produções em terapia eram criativas, tendo chegado a desenvolver um livro que contava sobre as coisas de que gostava - como comidas, filmes, animais.

Por meio desses desenhos, Pedro relatou ter amizade apenas com o irmão e com dois primos, de idade semelhante à sua. Em casa, passava muito tempo com a mãe, sendo ela sua principal companhia durante o dia. Também sentia medo de dormir no escuro à noite, dizendo que sentia "medo de olhar e ver alguma coisa no corredor". Sobre a escola, dizia que não tinha amigos e que não gostava de copiar as matérias porque "precisava olhar para o quadro, enquanto, para fazer livrinhos, não"; relatou, ainda, que, "na escola, sabia tudo, era tudo mais fácil". Entendia, ainda, que seus colegas não gostavam de brincar como brincava, e que, na escola, gostava mais de jogar xadrez, mas não encontrava companheiro para o jogo. 
Considerando que o plano de terapia constava de buscar mudanças nos perfis de filho/ amigo/estudante de Pedro, o estímulo à sua independência foi buscado, no início, a partir, principalmente, de seus perfis de estudante e de amigo, uma vez que, para Pedro, essa problemática era mais facilmente percebida. Por meio dos desenhos, foi possibilitado que Pedro identificasse e se apropriasse das atividades que gostava de fazer e das que não gostava, procurando diferenciar o que era de seu ser e o que era dos outros, descortinando o saber-de-ser que vinha construindo na espontaneidade e que o estava impedindo de experimentar outras possibilidades de ser.

Com relação aos amigos da escola, percebeu que estava realizando escolhas que contribuíam para que se sentisse sozinho, e, diante do desejo que tinha de fazer novas amizades e de ter companheiros para suas brincadeiras, compreendeu que era necessário, em alguns momentos, partilhar das brincadeiras que a maioria dos colegas desenvolviam. Foi descobrindo, então, as brincadeiras de bola, o futebol, as cartas - que já possuía em casa e que passou a levar para o colégio, convidando os amigos para jogar -, o que promoveu uma ampliação em sua rede de relações, não deixando de fazer aquilo de que gostava (xadrez, por exemplo), mas relativizando suas escolhas.

Dessa forma, após Pedro reconhecer suas particularidades e a forma como estava fazendo suas escolhas a partir do rastreamento e da compreensão de sua história, passou por uma etapa de mudanças, através da qual percebeu que suas escolhas tinham implicações diretas para a concretização de seu desejo. Em consequência, através de ações mediadas pela terapia, alterou sua dinâmica de ser, o que gerou mudanças visualizadas nas sessões: demonstrava evidente amadurecimento na relação com a psicoterapeuta - tanto na realização de tarefas como nas reflexões que fazia -, alterou, inclusive, sua forma de expressar-se verbalmente, apresentando um modo de falar mais tranquilo, melhorou a letra nas produções escritas e também aumentou o cuidado com os desenhos, colagens e palavras cruzadas, tendo diminuído também os erros de português, comuns em crianças que passam pelo processo de alfabetização.

Além disso, a mãe relatava que era possível perceber as transformações do filho com relação às queixas iniciais, movimento que também foi percebido pelo pai e pela professora de Pedro. Especificamente com relação à queixa de agressividade, a mãe dizia que o filho estava mais tranquilo, que já era possível negociar e fazer acordos sem que ele se alterasse e que agora cumpria os combinados. Destaca-se que a mudança na expressão verbal de Pedro em terapia - mesmo que em nenhum momento ele tenha utilizado a agressão com a estagiária - foram encarados como mostras de que as conquistas relatadas pela mãe eram bastante concretas. Essa mudança possivelmente tenha também auxiliado Pedro a expressar-se de forma mais assertiva com seus novos amigos.

A partir dessas alterações na dinâmica de Pedro, que o levaram a viabilizar seus desejos, partiu-se para a segunda parte do plano de intervenção da terapia, a ser realizada com a mãe. Em uma última sessão antes que a mãe começasse a comparecer com mais frequência aos atendimentos, sem a presença do filho, realizou-se uma atividade em que Pedro foi requisitado a escrever sobre $o$ antes e o depois da terapia. Assim, escolheu uma folha de papel reciclado para o antes e uma folha branca para o depois, e escreveu: "Antes - escola: antes na escola eu não tinha muitos amigos e não fazia atividades lá; noite: tinha medo do escuro e usava minha lanterna. Depois - escola: agora eu tenho muitos amigos para brincar e faço todas as atividades; noite: eu não tenho medo do escuro e não uso a minha lanterna". Essa atividade, mais uma vez, deixou claro que Pedro havia se apropriado das mudanças realizadas e estava viabilizando-se a partir das alterações desejadas em sua personalidade.

A opção de fazer o atendimento com a mãe fundamentou-se na compreensão de que 
a família desempenha papel fundamental na construção do ser do indivíduo e precisa ser implicada no processo psicoterapêutico quando o sujeito em terapia é uma criança. Segundo Sartre, "a pessoa vive e conhece mais ou menos claramente a sua condição através de sua pertinência a grupos" (1978b, p.140). Além disso, para Sartre, o ideal é que a família se relacione a partir de uma estrutura de grupo organizado, em função de seu papel de mediadora na estruturação do projeto de ser dos sujeitos. Nessa forma de organização, existe um projeto comum, que todos se esforçam para realizar. A ação é coletiva, existe um compartilhamento de objetivos e, através de relações de reciprocidade, a superação da solidão dos participantes ocorre pelo tecimento entre seus membros (Schneider, 2002). Estabelece-se, assim, além de uma afetividade, uma mediação exercida pelo grupo, através da qual "o outro torna-se um meio para me realizar, assim como eu a ele"( p. 224).

Nas sessões em que foi atendida sem a presença de Pedro, Maria relatou sentir angústia proveniente da dificuldade que tinha de lidar com o que considerava "imprevistos" na relação com os filhos. Portanto, quando surgia algum impasse, como um pedido do filho para fazer algo sobre o qual ela não tinha certeza se deveria ou não permitir, angustiava-se diante da necessidade de posicionar-se diante dele e da possibilidade de lhe dizer "não". Retomando brevemente sua história, Maria compreendeu que tinha dificuldade de dizer "não" por medo de "frustrar o outro"; ao mesmo tempo, buscava controlar as ações e as reações dos filhos, o que, na verdade, era uma forma de induzi-los a agirem de forma que, mais tarde, ela não fosse novamente requisitada a tomar uma posição em relação às suas escolhas.

Diante desses relatos, buscou-se refletir sobre o projeto educativo que Maria desejava construir para os filhos, ou seja, o que gostaria de passar a eles, como gostaria de educá-los, o que gostaria que eles aprendessem, através do que foi possível a ela compreender que o "dizer não" fazia parte daquilo que ela entendia como necessário e que a levaria a concretizar a educação e o futuro que desejava para os filhos. Após algumas sessões fazendo essas reflexões, Maria relatou sentir-se mais segura com relação às suas ações na educação com os filhos, compreendendo que era necessário ter certeza de qual projeto de educação queria para eles, como uma escolha fundamental que a guiaria nas suas escolhas cotidianas.

Por fim, um último aspecto ainda foi trabalhado: a dificuldade que ela tinha de permitir que Pedro se tornasse independente dela e a dificuldade que ela própria tinha de desconstruir a centralidade de seu perfil de mãe, que gerava nela também uma dependência da presença dos filhos e da ocupação com as questões de ambos.

Segundo Sartre, sendo o indivíduo corpo e consciência, ele estabelece relações com a materialidade, com seu corpo, com a temporalidade e também com os demais. Nesta última, ou seja, na relação com o outro, o sujeito pode relacionar-se como um "ser para o outro" ou como um "ser com o outro". Na primeira forma de relação, o sujeito experimenta seu ser como se estivesse em poder do outro, em que "o outro desvelase a mim como o sujeito para o qual eu sou objeto" (Sartre, 1997, p. 441). Se, no entanto, os sujeitos se relacionam sendo um ser-com-ooutro, há relação de reciprocidade, ou seja, "o reconhecimento do outro enquanto liberdade, que viabiliza, portanto, a troca com o outro, onde um pode ser mediação para o outro" (Schneider, 2002, p. 219). Essa foi a forma de relacionar-se que se buscou construir em terapia entre a mãe de Pedro e ele, permitindo principalmente que a mãe, compreendendo o outro como "liberdade", permitisse uma relação de compartilhamento de projetos com os filhos, tomando decisões conjuntas, a partir de uma mediação mais crítica.

Após quatro sessões seguidas com Maria, optou-se por realizar novos atendimentos com Pedro, para que fosse trabalhada sua relação 
com a mãe e aspectos de sua independência e autonomia como filho - tendo em vista que a mãe havia relatado dificuldades para estimular esse amadurecimento nos filhos ao longo das sessões realizadas com ela. A autonomia. que antes estava sendo trabalhada a partir dos perfis de amigo e estudante de Pedro, passou a ser trabalhada também em seu perfil de filho, compreendendo-se que as reflexões realizadas levariam ao entendimento de que cada sujeito é responsável por suas escolhas e pelo seu projeto de ser. Segundo Maheirie, "escolher é, unicamente, atuar, realizar qualquer coisa no mundo concreto (...). Assim, seu significado corresponde (...) à objetivação da subjetividade que se concretiza a partir das determinações do contexto, do passado e em função do aindanão-feito, do futuro" (2002, p.36).

Em sessão posterior, trabalhando aspectos diretamente atrelados à sua relação com a mãe, Pedro foi levado a refletir sobre as consequências que a sua forma de se relacionar como filho tinha tanto para si como para a mãe, visto que, ao escolher para si, o indivíduo escolhe também para o outro. Apesar desse trabalho com ele, naquele momento, avaliou-se que as dificuldades de Pedro em adquirir autonomia advinham, principalmente, do modo como a mãe se relacionava com os filhos, já que, durante essas duas sessões, Pedro não demonstrou resistências em assumir as responsabilidades por suas tarefas e autocuidado.

Dessa forma, o trabalho em psicoterapia no processo de independência de Pedro esteve o tempo todo vinculado às reflexões realizadas com Maria, principalmente às consequências de suas escolhas e às suas responsabilidades ante si mesma e os outros. Por isso, após essas sessões com Pedro, duas novas sessões com sua mãe foram realizadas, quando foram abordadas questões relacionadas à sua própria independência com relação aos filhos, ou seja, à modificação de uma dinâmica caracterizada pela centralidade queo papel de mãe tinha em sua vida, que proporcionaria a Pedro novas possibilidades de experimentar-se como sujeito independente, mediadoem sua relação com a mãe.
Nas últimas sessões, portanto, além do processo de alta, os conteúdos trabalhados com Maria e com Pedro incluíram a compreensão política descrita por Sartre (1978b), relacionadas à responsabilidade que os indivíduos têm com relação aos seus projetos e também com os projetos de ser dos demais. Ambos puderam, então, compreender que escolher para si mesmo implica escolher também para o outro, e, além disso, para o contexto social mais amplo, tendo em vista que os sujeitos são sempre seres em relação e que constituem sua personalidade a partir da subjetivação da exterioridade, sendo a exterioridade criada também a partir da objetivação que fazem de sua subjetividade, em um processo dialético de construção individual e social.

Finalmente, a última sessão realizada com Pedro foi organizada de forma a permitir que conteúdos relacionados ao desligamento emergissem e que, em consequência, fossem trabalhados pela psicoterapeuta. Tendo à disposição materiais como lápis, revistas, folhas em branco, cola e tesoura - materiais bastante utilizados durante todo o processo - a Pedro foi sugerido realizar o que desejasse naquele tempo do atendimento. Diante da liberdade de escolha, pegou uma folha branca e disse; "vou fazer uma carta de adeus", quando então escreveu: "ADEUS. Nós aprendemos muitas coisas com você, mas é hora de ir embora e ainda tenho muitas e muitas coisas para aprender na escola, mas com minha professora, mas você eu sempre me lembrarei".

\section{Considerações finais}

Encerrado o atendimento de Pedro, considerase que, por se tratar de psicoterapia com uma criança, a participação ativa de Maria no processo criou condições para alcançar os objetivos estabelecidos ao longo das sessões. Ressalta-se que o pai de Pedro também foi chamado a participar do processo, mas seu comparecimento não foi possível tendo em vista seu horário de trabalho.

Assim, avalia-se que a psicoterapia, como nova mediação inserida nas relações de Pedro, 
possibilitou mudanças em seu eu, visto que, refletindo criticamente sobre si mesmo, fez mais do que assumir o que lhe foi imposto e superou o dever-ser para situar-se no horizonte do poder-ser, como descrito pela teoria. Por outro lado, destaca-se que a abordagem existencialista de J. P. Sartre, ao não reduzir o sujeito que busca a psicoterapia a uma queixa nem a um diagnóstico estanque, mas a compreendê-lo a partir de sua história e das relações que estabelece com a exterioridade, permite abarcar a diversidade dos fenômenos a serem trabalhados em terapia, considerando o homem um "eterno vir a ser", ou seja, aquele que se move para o futuro e que o faz em direção àquilo que ainda não é e ao que ainda pode realizar.

\section{Zuleica Pretto}

Doutoranda em Psicologia pela Universidade Federal de Santa Catarina, docente do curso de Psicologia e coordenadora do Serviço de Psicologia da Universidade do Sul de Santa Catarina, Florianópolis - SC - Brasil.

E-mail: zuleicapretto@yahoo.com.br

\section{Fabíola Langaro}

Mestre em Psicologia pela Universidade Federal de Santa Catarina, psicóloga hospitalar do Centro Hospitalar Unimed Joinville e docente do curso de Psicologia da Associação Catarinense de Ensino, Joinville - SC - Brasil.

E-mail: flangaro@hotmail.com

\section{Endereço para envio de correspondência:}

Avenida Campeche,1157, bloco A1, ap. 206, Campeche. Florianópolis - SC. CEP: 88063-300

Recebido 26/03/2010, Aprovado 29/11/2012.

Castro, D. J., \& Schneider, D. R. (1998). Contribuição do existencialismo moderno para a psicologia social crítica. Caderno de Psicologia: IP/UERJ, 8, 139-149.

Laing, R. D. (1987). O eu dividido: estudo existencial da sanidade e da loucura (5a ed.). Petrópolis, RJ: Vozes.

Langaro, F., Santos, G. B., \& Pretto, Z. (2009). Psicologia clínica existencialista na atenção básica à saúde: um relato de atuação. Psicologia: Ciência e Profissão, 29 (2), 394-405.

Maheirie, K. (2002, jan./jul.). Constituição do sujeito, subjetividade e identidade. Revista Interações, 7(13), 31-44.

Ribeiro, F. M. (1992). Metodologia terapêutica no existencialismo moderno.
Sartre, J-P. (1978a). O existencialismo é um humanismo. São Paulo: Abril Cultural. (Coleção Os Pensadores).

Sartre, J-P. (1978b). Questão de método. São Paulo: Abril Cultural. (Coleção Os Pensadores).

Sartre, J-P. (1997). O ser e o nada. (14a ed.). Petrópolis, RJ: Vozes.

Schneider, D. R. (2002). Novas perspectivas para a psicologia clínica: um estudo a partir da obra Saint Genet: Comédien et Martyr, de Jean-Paul Sartre. Tese de doutorado defendida no Programa de Pós-Graduação em Psicologia Clínica da Pontifícia Universidade Católica, São Paulo, SP. 